\title{
A Taxonomy of Quality Standard Adoption: Its Relationship with Quality Management and Performance in Tourism Organizations In Spain
}

\author{
Juan José Tarí \\ Business Management Department, University of Alicante, Alicante, Spain \\ Jorge Pereira-Moliner \\ Business Management Department, University of Alicante, Alicante, Spain \\ José F. Molina-Azorín \\ Business Management Department, University of Alicante, Alicante, Spain \\ María D. López-Gamero \\ Business Management Department, University of Alicante, Alicante, Spain \\ Received: 5 May 2020. Revision received: 5 June 2020. Accepted: 30 June 2020
}

\begin{abstract}
This work aims to identify quality standard adoption levels and their relationship with quality management practices and performance (customer, employee and social results, and organizational performance) in tourism organizations in Spain. This work uses 279 tourism organizations in the following subsectors: hotels, travel agencies, restaurants, and rural accommodations. The work applies cluster and regression analyses. Results show three levels of adoption and a lower degree of development of the continuous improvement dimension. Organizations with a significantly lower level of development of the quality standard have started to integrate the quality requirements in their daily practices to some extent and where continuous improvement practices are little developed. These organizations have significantly lower results than those organizations with higher adoption of quality. The results also indicate that a greater level of adoption of a quality standard leads to a higher development of QM practices. These results are interesting for managers, destination managers, and the wider tourism professional community. It contributes to supplementing previous studies about taxonomies of quality standard adoption in the particular case of tourism organizations in Spain and may serve as a starting point for further research on that topic.
\end{abstract}

Key Words: quality management; quality standard; performance; tourism organizations.

JEL Classification: M1, M11, M19

Reference: Tarí, J.J., Pereira-Moliner, J., Molina-Azorín, J.F., López-Gamero, M.D. (2020). A Taxonomy of Quality Standard Adoption: Its Relationship with Quality Management and Performance in Tourism Organizations In Spain. Journal of Tourism and Services, 21(11), 22-37. doi: 10.29036/jots.v11i21.151

\section{Introduction}

Prior research shows that organizations can carry out a full or a superficial adoption of quality standards (Naveh \& Marcus, 2005; Prajogo, 2011) and that the effects of quality initiatives on performance are mixed (Carmona-Márquez, Leal-Rodríguez, Leal-Millán, \& Vázquez-Sánchez, 2019; Dobrovič, Kmeco, Gallo, \& Gallo, 2019; Samson \& Terziovski, 1999; Sila \& Walczak 2017). These ideas suggest that it is interesting to understand when a quality standard may be effective. i.e., it may facilitate the creation of a quality and performance improvement culture. 


\section{JOURNAL OF TOURISM AND SERVICES}

Issue 21, volume 11, ISSN 1804-5650 (Online)

www.jots.cz

Existing quality standard studies mostly consider a homogeneous adoption of the standard, measuring it as a binary variable (certified and non-certified firms) (Benner \& Veloso, 2008; MartínezMartínez, Cegarra-Navarro, García-Pérez, 2018; Sánchez-Ollero, García-Pozo, \& Marchante-Mera, 2014; Sharma, 2005). A few studies have a wider scope and consider a heterogeneous adoption, using a set of items instead of binary variables (Ataseven, Prajogo, \& Nair, 2014; Briscoe, Fawcett, \& Todd, 2005; Jang \& Lin, 2008; Nair \& Prajogo, 2009; Naveh \& Marcus, 2005). Although homogeneous adoption studies are important to understand the quality standards, their drivers and outcomes, only those studies on heterogeneous adoption can really measure various degrees of adoption of a quality standard, and thus measure the relationship between adoption levels of a quality standard and quality management (QM) practices and performance. Being familiar with a taxonomy of adoption of a quality standard is interesting for managers to identify strengths and weaknesses and, in this way, identify how to advance in the level of adoption to increase their quality commitment and improve performance. Subsequently, managers can carry out a diagnosis of their quality commitment and business processes for improvement (Garza-Reyes, 2018).

Only a few studies identify a taxonomy of quality standard adoptions (Boiral, 2003; Boiral \& Roy, 2007). More works are needed to examine this issue considering other quality standards (e.g., other than the ISO 9001 standard) and other contexts (e.g., outside the manufacturing sector) (Heras-Saizarbitoria $\&$ Boiral, 2013). There is a lack of studies that identify a taxonomy of adoption of a quality standard in the case of quality standards other than the ISO 9001 standard and its relationship with QM practices and performance in service organizations.

This work focuses on the heterogeneous adoption of a specific quality standard for the tourism industry to address this gap. The aim of this paper is to identify a taxonomy of adoption of quality standards and its association with QM practices and performance. On this basis, this work contributes to previous literature in the following aspects. First, very few works identify empirically the levels of quality standard adoption. These few studies focus on the ISO 9001 standard (Boiral, 2003; Boiral \& Roy, 2007). The present study deals with a specific quality standard for the tourism industry; on the basis of these levels of adoption, their association with QM practices and performance is examined. This expands the results by Boiral (2003) and Boiral and Roy (2007) by identifying not only the levels of adoption of a specific standard in the tourist sector, but also pointing out its connection with QM and performance by showing differences by sectors. Second, the previous studies about heterogeneous adoption of quality standards concentrate mainly on manufacturing organizations and less attention is paid to the service sector and the case of the tourism industry. The present work focuses on the tourism industry in Spain, a critical sector in its economy. The World Economic Forum has described Spain as the most competitive country in the tourist sector in 2018. Tourism generates 11.1\% of GDP and 13\% of jobs in Spain (OECD, 2019). In addition, Spain ranks world's second by international tourist arrivals and by tourism receipts in 2017 (UNWTO, 2018).

\section{Literature review}

In the present paper, the levels of quality standard adoption are the different degrees of implementation of the quality standard requirements. An organization can adopt the requirements of any quality standard in different ways. The literature suggests a basic or advanced adoption (Cai \& Jun, 2008; Naveh \& Marcus, 2005) and uses one or two dimensions including different items to measure that adoption. In the present paper, two dimensions are used based on this prior research: daily practices and continuous improvement. Quality management is a management philosophy and a set of practices for managing an organization (Dale, Van der Wiele, \& Van Iwaarden, 2007). The most common QM practices are: leadership, planning, customer/stakeholder focus, supplier relationships, process management, data analysis, and employee management (Molina, Tarí, Claver, \& López, 2009; Kim, 


\section{JOURNAL OF TOURISM AND SERVICES}

Issue 21, volume 11, ISSN 1804-5650 (Online)

www.jots.cz

Kumar, \& Kumar, 2012). These are considered to measure QM practices. Regarding performance, prior research and business excellence models show that quality may influence positively on customer, employee and social results, and organizational performance (Bou-Llusar, Escrig-Tena, Roca-Puig, \& Beltrán-Martín, 2009; EFQM, 2012). These four results are considered in the present paper.

\subsection{Levels of adoption and performance}

In the QM field in general, several scholars identify different levels of implementation of QM and show that organizations with a higher level of development of QM practices achieve higher levels of performance in relation to customers, employees, efficiency and business (Lee, To, \& Yu, 2009; Yeung, Chan, \& Lee, 2003; Garza-Reyes, 2018).

Regarding levels of adoption of quality standards, Boiral (2003) and Boiral and Roy (2007) distinguish different degrees of adoption of the ISO 9001 standard. Boiral (2003) identifies three levels from a qualitative study: enthusiasts, ceremonial integrators and dissidents. The group with the highest level (enthusiasts) includes organizations with an ordered management system, where work practices comply with formally defined rules. In this case, the quality standard is part of the work routines. In the ceremonial integrators group, the implementation may be a more token one. The lowest level (dissidents) is made up of organizations which believe that the system is useless and show a resistance to change. They view the system as an instrument of control imposed by the management. The result is that the benefits are much less than those obtained by enthusiasts.

Boiral and Roy (2007) identify four groups in the adoption of the ISO 9001 standard on the basis of the reasons for certification, and establish the connection with results from a quantitative study: enthusiasts, integrators, ritual integrators and dissidents. The enthusiasts include organizations concerned about both internal and external reasons for the obtention of the quality certificate, and are those most convinced about the benefits of adopting the standard. These organizations will encounter fewer problems when implementing a quality standard and will obtain great benefits. The ritual integrators consider that the adoption of the standard is justified due to commercial reasons, even if its usefulness as a management tool is questionable. This lower interest in internal aspects leads to fewer benefits. Those organizations classified as integrators believe that internal reasons are more important than external ones, and this may lead them to encounter fewer problems in implementation and obtain greater benefits. The dissidents (the group with the lowest commitment to the standard) show little concern for internal and external reasons for certification, and adopt the standard in a token way, as they believe it is a source of bureaucracy and, therefore, its benefits are poor. Also, this group will have more problems to adopt other working methods which differ from those already in place.

These two works identify a level with a greater development (enthusiasts), another one with a poor development of the quality standard (dissidents) and an intermediate level (which Boiral \& Roy, in turn, divide into two levels). According to these ideas, a higher development of the requirements of a quality standard may lead to better results. For example, the studies about heterogeneous adoption of quality standards show that a greater development of the ISO 9001 standard requirements (e.g., training, customer focus, supplier focus ...) leads to improved customer results and employee results (Allur, Heras-Saizarbitoria, \& Casadesús, 2014; Ataseven et al., 2014; Bello-Pintado, Heras-Saizarbitoria, \& Merino-Díaz-de-Cerio, 2018; Cai \& Jun, 2018; Naveh \& Marcus, 2005; Psomas, Kafetzopoulos, \& Fotopoulos, 2013). For example, in the service sector, higher training, employee involvement, a more efficient use of customer data, and cooperation with the entire supply chain, make it possible to introduce improvements in the service (Clarke \& Hill, 2012; Hsieh \& Chuang, 2019). Similarly, in the case of the tourism industry, quality initiatives can also lead to positive impacts on employee results and customer results (Benavides-Velasco, Quintana-García, \& Marchante-Lara, 2014; Del Río-Rama, Álvarez-García, \& Oliveira, 2019; Kalemba \& Campa-Planas, 2017). 


\section{JOURNAL OF TOURISM AND SERVICES}

Issue 21, volume 11, ISSN 1804-5650 (Online)

www.jots.cz

In addition to the effects on customers and employees, some scholars show that quality standards affect other interest groups, such as, for instance, authorities (Posinska, Dahlgaard, \& Antoni, 2002), while other scholars state that quality initiatives have no impact on social results (Benavides-Velasco et al., 2014). In spite of these mixed results, in general terms, various works indicate that quality facilitates environmental (Curkovic, 2003) and social initiatives (Withanachchi, Handa, Karandagoda, Pathirage, Tennakoon, \& Pullaperuma, 2007), and therefore it could be considered that tourism organizations with a higher adoption of the quality standard may obtain better social results.

Prior research also shows that QM in general, and the quality standard in particular (Bou-Llusar et al., 2009; Nair \& Prajogo, 2009; Carmona-Márquez et al., 2019; Psomas, Pantouvakis, \& Kafetzopoulos, 2013) may have positive effects on organizational performance. This seems to indicate that organizations with higher levels of adoption of a quality standard are organizations with better organizational performance. All these ideas suggest that different levels of adoption of a quality standard can exist and that these different levels may be associated to different results (customer results, employee results, social results, and organizational performance):

Hypothesis 1: Tourism organizations that adopt the quality standard to a higher extent show significantly higher performance levels (customer, people, society and organizational).

\subsection{Levels of adoption and quality management practices}

Previous studies show that organizations with a higher commitment to a quality culture find it easier to adopt the requirements of a quality standard (Briscoe et al., 2005). One of the reasons, for instance, is that a quality culture causes the employees to be better trained, and training can facilitate the adoption of quality standards (Naveh \& Marcus, 2005). This means that QM can be a driver of quality standards. Nevertheless, the reverse association can also be possible. When an organization adopts a quality standard it usually defines its quality policy and objectives, offers training to employees, analyses customer feedback, improves its supplier relationships, etc. (Singh, 2008), in order to comply with the requirements of the quality standard. This compliance with the requirements may be a way of developing QM practices. In turn, this indicates that quality standards can be also an antecedent of QM practices. However, organizations may adopt the standard in a different way, and its benefits may also be different, and even, as some studies have suggested, there may be no benefits at all. For example, an organization may adopt a quality standard without achieving clear benefits and have bureaucracy problems (Boiral, 2003).

In this respect, the studies by Boiral (2003) and Boiral and Roy (2007) show that a higher development of the quality standard implies greater benefits and fewer human bureaucracy problems. This means that the employees believe in the requirements of the standard and are more proactive in their application to daily tasks, which leads to a more efficient development of QM practices. The following hypothesis can then be suggested for tourism organizations:

Hypothesis 2: A heterogeneous adoption of a quality standard explains significantly QM practices development in tourism organizations.

\section{Method}

\subsection{Population and sample}

The population considered is the 725 firms certified with the Q tourist quality standard of the Spanish Institute for Tourism Quality (ICTE) of the following subsectors: hotels, travel agencies, 


\section{JOURNAL OF TOURISM AND SERVICES}

Issue 21, volume 11, ISSN 1804-5650 (Online)

www.jots.cz

restaurants and rural accommodations. A structured questionnaire that includes closed questions was sent to these 725 organizations in three waves, by ordinary post and e-mail simultaneously, with 279 answers by the quality manager (see Table 1).

Table 1. Absolute and relative frequency of each subsector (sample and population)

\begin{tabular}{lccc}
\hline \multicolumn{1}{c}{ Subsector } & Sample (\% Frequency) & $\begin{array}{c}\text { Population (\% } \\
\text { Frequency) }\end{array}$ & $\begin{array}{c}\text { Response rate by } \\
\text { subsector }\end{array}$ \\
\hline Hotels & $170(60.9 \%)$ & $415(57.2 \%)$ & $41.0 \%$ \\
Travel agencies & $20(7.2 \%)$ & $37(5.1 \%)$ & $54.5 \%$ \\
Restaurants & $54(19.4 \%)$ & $179(24.7 \%)$ & $30.2 \%$ \\
Rural accommodations & $35(12.5 \%)$ & $94(13.0 \%)$ & $37.2 \%$ \\
TOTAL & 279 & 725 & $38.5 \%$ \\
\hline
\end{tabular}

Before sending the final questionnaire to the population, a pre-test was carried out with three managers in three tourism bodies, two managers in two hotels, one manager in a restaurant, and a quality consultant.

In order to check the representativity of the sample, Student's t test between early and late respondents shows that there are no significant differences between the variables considered in this work (Armstrong \& Overton, 1977).

\subsection{Variables}

The study uses a seven-point scale for the following variables:

- Heterogeneous adoption of quality standard. Two constructs are used (Table 2): daily practices (five items from Briscoe et al., 2005; Christmann \& Taylor, 2006; Naveh \& Marcus, 2005; Tarí, Molina-Azorín, Pereira-Moliner, \& López-Gamero, 2020) and continuous improvement (five items from Briscoe et al., 2005; Nair \& Prajogo, 2009; Naveh \& Marcus, 2005; Tarí et al., 2020).

- Customer results. This construct includes five items (Table 3) on the basis of studies on quality (Bou-Llusar et al., 2009; Curkovic, Melnyk, Calantone, \& Handfield, 2000; Tarí, Molina, \& Castejón, 2007) and tourism-specific studies (Deng, Yeh, \& Sung, 2013).

- Employee results. This construct includes six items (Table 3) on the basis of studies on quality (Curkovic et al., 2000; Bou-Llusar et al., 2009) and tourism-specific studies (Yeh, 2013).

- Social results. This construct includes three items, on the basis of quality management studies and tourism-specific studies (Bou-Llusar et al., 2009; Kim, Lee, \& Prideaux, 2014; Tarí et al., 2007).

- Organizational performance. Construct consisting of four items (Table 3) on the basis of the studies by Tarí et al. (2007) and Bou-Llusar et al. (2009).

- Quality management practices. This construct includes eight items related to QM practices based on Pereira-Moliner, Claver-Cortés, Molina-Azorín, and Tarí (2012) (Table 4). 
JOURNAL OF TOURISM AND SERVICES

Issue 21, volume 11, ISSN 1804-5650 (Online)

www.jots.cz

Table 2. Heterogeneous adoption of quality standards

$\begin{array}{rc} & \text { Factor } \\ & 0.833 \\ & 0.877 \\ & 0.412 \\ & 0.753 \\ & 0.832 \\ \text { Eigenvalue per factor } & 2.893 \\ \text { \% of variance explained } & 57.851 \% \\ \text { Correlation matrix determinant } & 0.118 \\ \text { Kaiser-Meyer-Olkin index } & 0.745 \\ \text { Barlett's significance test of sphericity } & 0.000 \\ \text { Cronbach's alpha } & 0.913\end{array}$

Continuous improvement

- $\quad$ CI1.The development of the quality system makes it possible to introduce new improvement practices

- $\quad$ CI2. The quality standard has led the organization to discover improvement opportunities

- $\quad$ CI3. Investing time and resources in the quality standard is a starting point towards the implementation of other more advanced practices

- CI4. Investing time and resources in the quality standard helps to reflect on the way work is done in the firm and improve our work

- CI5. Investing time and resources in the quality standard is seen as an opportunity to innovate in our organization 
JOURNAL OF TOURISM AND SERVICES

Issue 21, volume 11, ISSN 1804-5650 (Online)

www.jots.cz

Table 3. Performance

Customer results

- CR1. Increased customer satisfaction

Factor

0.898

- $\quad$ CR2. Increased quality of service

0.806

- CR3. Increased customer loyalty

0.921

- CR4. Increased valuations in web 2.0 and social networks

0.831

- $\quad$ CR5. Reduced customer complaints

0.855

$$
\begin{array}{r}
\text { Eigenvalue per factor } \\
\text { \% of variance explained } \\
\text { Correlation matrix determinant } \\
\text { Kaiser-Meyer-Olkin index } \\
\text { Barlett's significance test of sphericity } \\
\text { Cronbach's alpha }
\end{array}
$$

Employee results

- ER1. Increased employee satisfaction

- ER2. Increased employee motivation

- ER3. Increased employee productivity

- ER4. Improving working conditions of employees

0.876

- ER5. Reduced absenteeism of employees

0.826

- ER6. Reduction of employee complaints

$$
\begin{array}{r}
\text { Eigenvalue per factor } \\
\% \text { of variance explained } \\
\text { Correlation matrix determinant } \\
\text { Kaiser-Meyer-Olkin index } \\
\text { Barlett's significance test of sphericity } \\
\text { Cronbach's alpha }
\end{array}
$$

0.867

Social results

- SR1. Increased environmental protection (reduction of resource consumption, pollution reduction)

- $\quad$ SR2. Improving the ethical behaviour of the organization

- $\quad$ SR3. Increased levels of prevention of risks to health and safety (risk reduction accidents, etc.)

$$
\begin{array}{r}
\text { Eigenvalue per factor } \\
\% \text { of variance explained } \\
\text { Correlation matrix determinant } \\
\text { Kaiser-Meyer-Olkin index } \\
\text { Barlett's significance test of sphericity } \\
\text { Cronbach's alpha }
\end{array}
$$

Organizational performance

- OP1. Increased market share

- OP2. Increased sales

- OP3. Increased profitability

- OP4. Cost reduction 
JOURNAL OF TOURISM AND SERVICES

Issue 21, volume 11, ISSN 1804-5650 (Online)

www.jots.cz

Table 4. Quality management practices

\begin{tabular}{|c|c|}
\hline 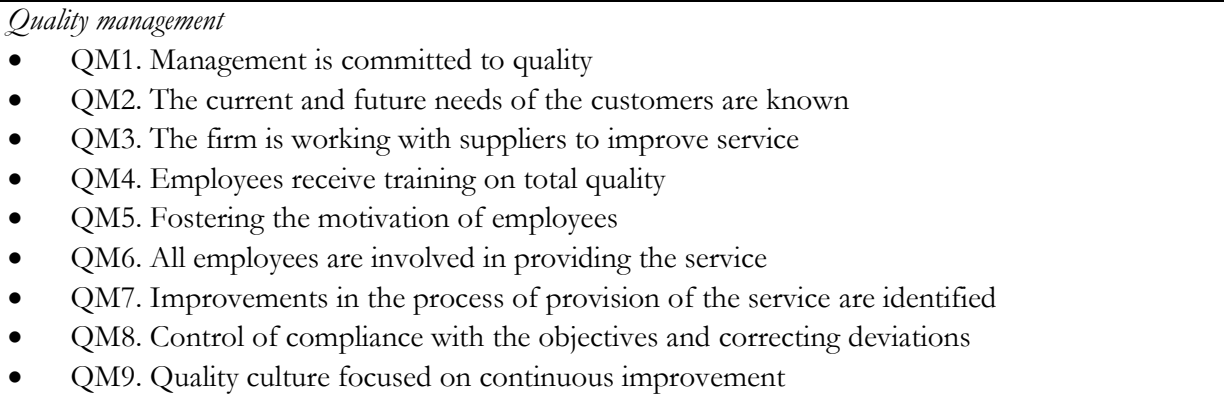 & $\begin{array}{l}\text { Factor } \\
0.738 \\
0.732 \\
0.717 \\
0.765 \\
0.792 \\
0.796 \\
0.821 \\
0.820 \\
0.839 \\
5.493 \\
61.034 \% \\
0.003 \\
0.904 \\
0.000 \\
0.917\end{array}$ \\
\hline
\end{tabular}

As these variables are perceptual, validity and reliability are checked (see Tables 2, 3, and 4). Content validity is ensured by means of an extensive literature review and the opinion of tourism managers. Construct validity is assessed by means of factor analysis. All the items making up the constructs converge into one single factor. Regarding criterion validity, the correlation between the environmental result and the variables measured in this study are significantly related $(p=0.000)$. The environmental result was measured by means of seven items (Wagner, 2009). Finally, reliability is examined by means of Cronbach's alpha ( $>0.7$ in all factors).

\section{Results}

\subsection{Levels of quality standard adoption}

This section identifies levels of quality standard adoption using a two-step cluster analysis (Bacher, 2000; Everitt, Landau, \& Leese, 2001; Bencsik, Tóbiás Kosár, \& Machová, 2018). The analysis identifies three groups according to the level of adoption of daily practices and continuous improvement (Table 5). The solution shown by the cluster quality indicator is a good one, since a level of 0.6 is reached (Kaufman \& Rousseeuw, 2005). Also, after applying a discriminant analysis where the independent variables are quality practices and continuous improvement and the clustering variable is the classification of each firm in its corresponding group, it is found that $91 \%$ of cases have been correctly classified by applying the cluster analysis in two stages. The remaining $9 \%$ is due to firms which did not respond to some of the items and, therefore, could not be classified. 


\section{JOURNAL OF TOURISM AND SERVICES}

Issue 21, volume 11, ISSN 1804-5650 (Online)

www.jots.cz

Table 5. Groups of tourist firms based on daily practices and continuous improvement

\begin{tabular}{|c|c|c|c|c|c|}
\hline & $\begin{array}{c}\text { Group } 1 \\
\mathrm{~N}=51(19.58 \%)\end{array}$ & $\begin{array}{c}\text { Group 2 } \\
\mathrm{N}=118(45.0 \%)\end{array}$ & $\begin{array}{c}\text { Group } 3 \\
\mathrm{~N}=93(35.5 \%)\end{array}$ & F ANOVA & Schefeé test \\
\hline Daily practices & 4.478 & 5.325 & 6.583 & $206.689 * * *$ & $3>2>1 * * *$ \\
\hline - $\quad \mathrm{DP} 1$ & 4.67 & 5.64 & 6.76 & $77.552^{* * *}$ & $3>2>1 * * *$ \\
\hline - $\quad$ DP2 & 4.65 & 5.86 & 6.89 & $115.081 * * *$ & $3>2>1 * * *$ \\
\hline - $\quad \mathrm{DP} 3$ & 4.24 & 4.21 & 5.92 & $90.088^{* * *}$ & $3>2 * * * ; 3>1 * * *$ \\
\hline - $\quad$ DP4 & 4.27 & 5.35 & 6.56 & $78.791 * * *$ & $3>2>1 * * *$ \\
\hline - $\quad$ DP5 & 4.57 & 5.57 & 6.77 & $111.493^{* * *}$ & $3>2>1 * * *$ \\
\hline Continuous improvement & 3.604 & 5.442 & 6.529 & $331.981 * * *$ & $3>2>1 * * *$ \\
\hline - $\quad \mathrm{CI} 1$ & 4.14 & 5.67 & 6.65 & $182.393 * * *$ & $3>2>1 * * *$ \\
\hline - $\quad \mathrm{CI} 2$ & 3.84 & 5.63 & 6.53 & $138.782^{* * *}$ & $3>2>1 * * *$ \\
\hline - $\quad \mathrm{CI} 3$ & 3.04 & 5.04 & 6.34 & $193.349 * * *$ & $3>2>1 * * *$ \\
\hline - $\quad \mathrm{CI} 4$ & 3.67 & 5.50 & 6.59 & $169.584 * * *$ & $3>2>1 * * *$ \\
\hline - $\quad \mathrm{CI} 5$ & 3.33 & 5.37 & 6.54 & $216.797 * *$ & $3>2>1 * * *$ \\
\hline Customer results & 3.437 & 4.821 & 5.435 & $41.006 * * *$ & $3>1 * * * ; 3>2 * *$ \\
\hline Employee results & 2.888 & 4.182 & 5.194 & $57.430 * * *$ & $3>2>1 * * *$ \\
\hline Social results & 3.386 & 4.920 & 5.770 & $58.763^{* * *}$ & $3>2>1 * * *$ \\
\hline $\begin{array}{l}\text { Organizational } \\
\text { performance }\end{array}$ & 2.537 & 3.878 & 4.819 & $46.139 * * *$ & $3>2>1 * * *$ \\
\hline Quality management & 4.99 & 5.75 & 6.56 & $88.62 * * *$ & $3>2>1 * * *$ \\
\hline - $\quad$ QM1 & 5.63 & 6.42 & 6.89 & $38.88 * * *$ & $3>2>1 * * *$ \\
\hline - $\quad \mathrm{QM} 2$ & 5.20 & 5.75 & 6.43 & $30.32 * * *$ & $2>1 * * ; 3>2$ and $1 * * *$ \\
\hline - $\quad$ QM3 & 4.84 & 5.50 & 6.45 & $38.59 * * *$ & $2>1 * * ; 3>2$ and $1 * * *$ \\
\hline - $\quad$ QM4 & 4.68 & 5.50 & 6.53 & $55.03 * * *$ & $3>2>1 * * *$ \\
\hline - $\quad$ QM5 & 4.71 & 5.38 & 6.40 & $41.44 * * *$ & $2>1 * * ; 3>2$ and $1 * * *$ \\
\hline - $\quad$ QM6 & 5.10 & 5.59 & 6.49 & $21.72 * * *$ & $2>1 * ; 3>2$ and $1 * * *$ \\
\hline - $\quad$ QM7 & 4.72 & 5.70 & 6.54 & $69.61 * * *$ & $3>2>1 * * *$ \\
\hline - $\quad$ QM8 & 4.80 & 5.92 & 6.58 & $63.32^{* * *}$ & $3>2>1 * * *$ \\
\hline - $\quad$ QM9 & 5.24 & 5.98 & 6.81 & $56.87 * * *$ & $3>2>1 * * *$ \\
\hline
\end{tabular}

Table 5 shows the following three level of adoption of quality standard:

Group 1 - Basic adoption: this group shows the lowest values in each and every variable analysed. A relevant point is that, when comparing the averages for the items in the different groups, this group shows the lowest averages in all the continuous improvement items, compared to daily practices. This is not the case in the other groups. This group has little developed continuous improvement practices, and daily practices somewhat about the average in a 7-point scale. Also, this group has clear differences with Group 3 regarding the item "Audits are prepared at the last minute". These values indicate that the level of implementation of the quality standard is not a very advanced one, because these organizations prepare the audits at the last minute and do not have a high commitment to continuous improvement. This suggests that these organizations have integrated the requirements of the standard to some extent, but still have a token implementation of the standard. These organizations have the lowest results regarding customers, employees, society and organizational performance.

Group 2 - Medium adoption: this group shows good levels of adoption in all the items. This group has a higher level of integration of the quality requirements in work routines than group 1, although it does not show significant differences with group 1 regarding the item "Audits are prepared at the last minute". This indicates that, although the integration is greater than in the previous group, they still have 


\section{JOURNAL OF TOURISM AND SERVICES}

Issue 21, volume 11, ISSN 1804-5650 (Online)

www.jots.cz

to progress in order to reach full adoption of the quality standard. These organizations have a greater level of adoption and better results than the previous group.

Group 3 - Advanced adoption: this group includes the tourism firms which develop daily and continuous improvement practices in a more proactive way, which implies a wider adoption of the quality standard. This group includes organizations with a greater degree of integration of the quality standard in their work routines, with greater differences compared to the other two groups regarding quality practices and continuous improvement, and in the preparation of audits. These organizations do not prepare audits at the last minute, and show a real commitment to continuous improvement. These are the organizations which get the quality standard to form part of corporate management, and benefit from the standard to a greater extent, since they manage to advance in continuous improvement. All this enables them to obtain high levels of results regarding customer, employee, society and organizational performance.

\subsection{Hypotheses testing}

The results in Table 5 shows that those organizations with a higher development of the standard have better customer, employee and social results, and better organizational performance, supporting hypothesis 1 . This higher adoption could lead to a greater quality culture. This issue is also examined in Table 5. Table 5 shows that tourism organizations with a lower level of implementation of quality standard consider that quality is not a critical issue and develop quality management practices to a lower extent compared to other groups. Table 5 shows that the degree of development of QM practices in group 1 is significantly lower than in group 3 . Thus, tourism organizations in group 3 with a greater development of the quality standard develop the QM practices to a wider extent, whereas those with a less advanced development of the standard have a weaker quality culture. Group 1 includes tourism organizations where the quality standards are not a relevant managerial variable. This group represents $19.58 \%$ of the sample. Group 2 includes tourist firms with scores below the average. They represent $45 \%$ of the sample. Group 3 is formed by 93 tourist firms, that is, approximately $36 \%$ of the sample. The three groups show that the item with the highest score is "management is committed to quality" followed by "quality culture focused on continuous improvement". On the other hand, the Schefee test indicates that all items in the Group 3 are significantly greater than the Group 2 and 1.

Accordingly, when tourism organizations are more proactive with the quality standard requirements, they use more quality tools, there is a higher commitment to quality by top management, they consider quality as a strategic factor and use more data to improve processes. This means that they adopt QM practices in a more advanced way. To reinforce this idea, Table 6 shows regression analyses where QM is the dependent variable and daily practices and continuous improvement are independent variables. Table 6 shows that those tourism firms applying the requirements of the standard in their daily activities and advance towards continuous improvement are those firms most committed to QM practices. These results indicate that hypothesis 2 is clearly supported for hotels and restaurants and partially supported for travel agencies and country houses (see Table 6). 
JOURNAL OF TOURISM AND SERVICES

Issue 21, volume 11, ISSN 1804-5650 (Online)

www.jots.cz

Table 6. Regression analyses

\begin{tabular}{|c|c|c|c|c|}
\hline & Daily practices & $\begin{array}{l}\text { Continuous } \\
\text { improvement }\end{array}$ & $\mathrm{R}^{2}$ & $\mathrm{~F}$ \\
\hline \multicolumn{5}{|c|}{ Total sample } \\
\hline QM & 0.484 & 0.379 & 0.595 & $267.193^{* * *}$ \\
\hline $\mathrm{T}$ & $11.617^{* * *}$ & $9.080 * * *$ & & \\
\hline VIF & 1.556 & 1.556 & & \\
\hline \multicolumn{5}{|c|}{ Hotels } \\
\hline QM & 0.538 & 0.392 & 0.713 & $201.299 * * *$ \\
\hline $\mathrm{T}$ & $9.737 * * *$ & $7.095^{* * *}$ & & \\
\hline VIF & 1.717 & 1.717 & & \\
\hline $95 \%$ confidence intervals & $(0.416 ; 0.625)$ & $(0.224 ; 0.399)$ & & \\
\hline \multicolumn{5}{|c|}{ Travel agencies } \\
\hline QM & 0.649 & 0.198 & 0.871 & $12.993^{* * *}$ \\
\hline $\mathrm{T}$ & $3.314 * *$ & 1.009 & & \\
\hline VIF & 1.612 & 1.612 & & \\
\hline $95 \%$ confidence intervals & $(0.215 ; 0.977)$ & $(-0.132 ; 0.373)$ & & \\
\hline \multicolumn{5}{|c|}{ Restaurants } \\
\hline QM & 0.399 & 0.356 & 0.374 & $15.664 * * *$ \\
\hline $\mathrm{T}$ & $3.241 * *$ & $2.890 * *$ & & \\
\hline VIF & 1.190 & 1.190 & & \\
\hline $95 \%$ confidence intervals & $(0.123 ; 0.525)$ & $(0.065 ; 0.364)$ & & \\
\hline \multicolumn{5}{|c|}{ Rural accommodations } \\
\hline QM & 0.108 & 0.613 & 0.400 & $9.321 * * *$ \\
\hline $\mathrm{T}$ & 0.625 & $3.534 * *$ & & \\
\hline VIF & 1.254 & 1.254 & & \\
\hline $95 \%$ confidence intervals & $(-0.124 ; 0.231)$ & $(0.120 ; 0.460)$ & & \\
\hline
\end{tabular}

In travel agencies, only daily practices have an impact on QM practices. This could be due to the fact that these organizations have a simpler development of the standard, actually develop daily practices to a lesser extent when compared mainly to hotels and restaurants. Such lower development, although it does allow them to advance in quality management, does not enable them to reach an advanced level, because their commitment to continuous improvement is lower than in other sectors. Another reason could be the frequent use of franchises as an operational form in Spanish travel agencies. This operational form standardizes daily practices, but may delegate continuous improvement practices upon franchisees.

In rural accommodations, only continuous improvement makes it possible to advance in quality management. This may be due to the fact that in rural accommodations the purpose is to attain a quality standard differentiating them from hotels, by offering more personal services and experiences for tourists, and although the level of continuous improvement is lower than in hotels and restaurants, such continuous improvement (either through incremental or radical improvement) is what allows them to distinguish themselves.

\section{Discussion and conclusions}

The study identifies a taxonomy of quality standard adoptions and their relationship with QM practices and performance. First, regarding levels of adoption of quality standards, results show three levels of adoption and a lower degree of development of the continuous improvement dimension. This indicates an area for improvement mainly for Groups 1 and 2. The first group is made up of organizations with a significantly lower level of development of the quality standard than the other two groups. These are organizations that have started to integrate the quality requirements in their daily practices to some extent, but less than the other two groups, and where continuous improvement practices are little developed. These organizations have significantly lower results than the other two groups, and would be 


\section{JOURNAL OF TOURISM AND SERVICES}

Issue 21, volume 11, ISSN 1804-5650 (Online)

www.jots.cz

similar to the "dissidents" group as described by Boiral (2003) and Boiral and Roy (2007). Group 2, although it has a higher degree of adoption, still has to make some progress for the quality requirements to be part of corporate management. Group 3 would consist of organizations which develop the standard requirements in an advanced way, showing high management commitment and a more advanced commitment to continuous improvement. This allows them to obtain better results than the other two groups, which could include them within the "enthusiasts" group as described by Boiral (2003) and Boiral and Roy (2007). These organizations integrate the quality requirements in their operations, do not prepare the audits at the last minute and believe in the continuous improvement philosophy.

This study supports Boiral (2003) and Boiral and Roy (2007) and expands their results to the case of a different quality standard (tourism quality) and another context (the tourist sector). The result also supports previous studies that indicate that, the greater the development of the requirements, the more likely the organization is to improve its results (Ataseven et al., 2014; Naveh \& Marcus, 2005). These positive effects may be reflected in employee, society, and customer results, and in organizational performance. The results also expand previous studies that emphasize the operational and business benefits (Nair \& Prajogo, 2009; Naveh \& Marcus, 2005) by indicating that there are significant differences concerning customer, employee and society results.

Second, the results also indicate that different levels of adoption of quality standards are associated to different levels of development of quality practices. Although a quality culture facilitates the implementation of a quality standard, the reverse association is also possible, that is, a greater level of adoption of a quality standard leads to a higher development of QM practices when the adoption is a wider one. As a consequence, a higher level of adoption leads to QM and therefore a higher level of adoption of a quality standard is a driver of QM practices. In this respect, the most important aspects in the development of QM practices are the following (see Table 2):

- The quality system is part of the work routines and audits are not prepared at the last minute.

- Time and resources are invested in reflecting on how the firm works and how it can improve the way it works and introduce innovations.

\subsection{Managerial implications}

Firstly, managers must understand that the quality standard by itself does not lead to really have a QM system. It may be only the beginning and help towards completing that path. If the organization adopts the standard but top management commitment is not a high one, the audits are prepared at the last minute and there are no continuous improvement activities (or they are very few), the organization may obtain and maintain a quality certificate, but it will integrate the quality standard requirements in a token way, and therefore it will not fully benefit from the quality standard. In this respect, managers can use items used for daily practices and continuous improvement variables as a way to carry out an initial self-assessment in order to detect strengths and weaknesses, and on such basis develop actions in order to increase their degree of commitment to the quality standard requirements. All this will allow them to improve customer, employee and society results and organizational performance. Thus, the most important aspects for them are integrating the quality standard within work routines, not preparing the audits at the end, investing time and resources in improving work and introducing innovations. These aspects will help hotel and restaurant managers to develop a greater commitment to quality and to develop quality practices to a greater extent. For travel agency managers, it is more important to focus on daily practices in order to progressively develop a quality culture. In other words, travel agency managers must achieve an integration of the requirements of quality standard in their daily activities and use audits to identify improvements. This will allow them to develop continuous improvement to a 


\section{JOURNAL OF TOURISM AND SERVICES}

Issue 21, volume 11, ISSN 1804-5650 (Online)

www.jots.cz

greater extent. In the case of rural accommodations managers, it is more important to focus their strategies on continuous improvement initiatives to increase their level of QM.

\subsection{Limitations and future research}

A limitation in the present work is that it has analysed the answers of quality managers in various tourism organizations. Also, the sample of rural accommodations and travel agencies is a reduced one. As future lines of research, firstly, we could suggest carrying out qualitative studies using interviews with different managers and employees as a way of obtaining different perceptions regarding the standard. Also, given the importance of the organization's staff for the adoption of a quality standard, another interesting line of research would be examining the different roles, characteristics and relationships among employees, which could lead to different degrees of commitment to the quality standard. Secondly, it may be relevant to analyse the relationships examined in the present work distinguishing between certified firms and firms not possessing such certification, including, for instance, other types of services. It may also be interesting to carry out this study with a larger sample, mainly consisting of travel agencies and rural accommodations and even to replicate this study in contexts other than Spanish tourism organizations.

\section{Acknowledgments}

This study has been carried out as part of research project ECO2012-36316, funded by the Spanish government (National R\&D\&i Plan). Thanks are due to Dr. Miguel Ángel Campos-Pardillos, from the English Department at the University of Alicante, for the language revision of this paper.

\section{References}

1. Allur, E., Heras-Saizarbitoria I., \& Casadesús, M. (2014). Internalization of ISO 9001: a longitudinal survey. Industrial Management \& Data Systems, 114, 872-885.

2. Armstrong, J.S., \& Overton, T.S. (1977). Estimating non-response bias in mail surveys. Journal of Marketing Research, 14, 396-402.

3. Ataseven, C., Prajogo, D.I., \& Nair, A. (2014). ISO 9000 internalization and organizational commitment-implications for process improvement and operational performance. IEEE Transactions on Engineering Management, 61, 5-17.

4. Bacher, J. (2000). A probabilistic clustering model for variables of mixed type. Quality and Quantity, 34, 223-235.

5. Bello-Pintado, A., Heras-Saizarbitoria, I., \& Merino-Díaz-de-Cerio, J. (2018). Work-performance and internalisation of ISO 9000 standards: a shop floor workers perspective. Total Quality Management \& Business Excellence, in press.

6. Benavides-Velasco, C.A., Quintana-García, C., \& Marchante-Lara, M. (2014). Total quality Management, corporate social responsibility and performance in the hotel industry. International Journal of Hospitality Management, 41, 77-87.

7. Bencsik, A., Tóbiás Kosár, S., \& Machová, R. (2018). Corporate Culture in Service Companies that Support Knowledge Sharing, Journal of Tourism and Services, 9, 7-13.

8. Benner, M.J., \& Veloso, F.M. (2008). ISO 9000 practices and financial performance: a technology coherence perspective. Journal of Operations Management, 26, 611-629.

9. Boiral, O. (2003). ISO 9000: outside the iron cage. Organization Science, 14, 720-737. 


\section{JOURNAL OF TOURISM AND SERVICES}

Issue 21, volume 11, ISSN 1804-5650 (Online)

www.jots.cz

10. Boiral, O., \& Roy, M.J. (2007). ISO 9000: integration rationales and organizational impacts. International Journal of Operations \& Production Management, 27, 226-247.

11. Bou-Llusar, J.C., Escrig-Tena, A.B., Roca-Puig, V., \& Beltrán-Martín, I. (2009). An empirical assessment of the EFQM Excellence Model: Evaluation as a TQM framework relative to the MBNQA Model. Journal of Operations Management, 27, 1-22.

12. Briscoe, J.A., Fawcett, S.E., \& Todd, R.H. (2005). The implementation and impact of ISO 9000 among small manufacturing enterprises. Journal of Small Business Management, 43, 309-330.

13. Cai, S., \& Jun, M. (2018). A qualitative study of the internalization of ISO 9000 standards: the linkages among firms' motivations, internalization processes, and performance. International Journal of Production Economics, 196, 248-260.

14. Christmann, P., \& Taylor, G. (2006). Firm self-regulation through international certificable standards: determinants of symbolic versus substantive implementation. Journal of International Business Studies, 37, 863-878.

15. Clarke, M., \& Hill, S. (2012). Promoting employee wellbeing and quality service outcomes: The role of HRM practices. Journal of Management \& Organization, 18, 702-713.

16. Carmona-Márquez, F.J., Leal-Rodríguez, A.L., Leal-Millán, A.G., \& Vázquez-Sánchez, A.E. (2019). Does the isomorphic implementation of the TQM philosophy effectively lead to the simultaneous attainment of legitimacy and efficiency targets? Journal of Management \& Organization, in press, 1-24.

17. Curkovic, S. (2003). Environmentally Responsible Manufacturing: The development and validation of a measurement model. European Journal of Operational Research, 146, 130-155.

18. Curkovic, S., Melnyk, S., Calantone, R., \& Handfield, R. (2000). Validating the Malcolm Baldrige National Quality Award framework through structural equation modelling. International Journal of Production Research, 38, 765-791.

19. Dale, B., Van der Wiele, A., \& Van Iwaarden, J. (2007). Managing Quality (5th ed.). Blackwell.

20. Del Río-Rama, M.C., Álvarez-García, J., \& Oliveira, C. (2019). Quality practices and their influence on customer results: an empirical study. Current Issues in Tourism, 22, 806-826.

21. Deng, W.J., Yeh, M.L., \& Sung, M.L. (2013). A customer satisfaction index model for international tourist hotels: Integrating consumption emotions into the American Customer Satisfaction Index. International Journal of Hospitality Management, 35, 133-140.

22. Dobrovič, J., Kmeco, L., Gallo, P., \& Gallo jr., P. (2019). Implications of the Model EFQM as a Strategic Management Tool in Practice: A Case of Slovak Tourism Sector. Journal of Tourism and Services, 10, 47-62

23. EFQM (2012). EFQM model 2013, EFQM, Brussels, Belgium.

24. Everitt, B., Landau, S., \& Leese, M. (2001). Cluster Analysis, Arnold, London, UK.

25. Garza-Reyes, J.A. (2018). A systematic approach to diagnose the current status of quality Management systems and business processes. Business Process Management Journal, 24, 216-233.

26. Heras-Saizarbitoria, I., \& Boiral, O. (2013). ISO 9001 and ISO 14001: Towards a Research Agenda on Management System Standards. International Journal of Management Reviews, 15, 47-65.

27. Hsieh, Y-H., \& Chuang, I-C. (2019). Evaluation of key factors for service experience: a comparison of tourism factories and international tourism hotels. Tourism Economics, in press: 133.

28. Jang, W., \& Lin, C-I. (2008). An integrated framework for ISO 9000 motivation, depth of ISO implementation and firm performance. The case of Taiwan. Journal of Manufacturing Technology Management, 19, 194-216.

29. Kalemba, N., \& Campa-Planas, F. (2017). The quality effect on the profitability of US airline companies. Tourism Economics, 24, 251-269.

30. Kaufman, L.. \& Rousseeuw, P.J. (2005). Finding Groups in Data: An Introduction to Cluster Analysis, Wiley Series in Probability and Statistics, Hoboken, New Jersey, NJ. 


\section{JOURNAL OF TOURISM AND SERVICES}

Issue 21, volume 11, ISSN 1804-5650 (Online)

www.jots.cz

31. Kim, D.Y., Kumar, V., \& Kumar, U. (2012). Relationship between quality management practices and innovation. Journal of Operations Management, 30, 295-312.

32. Kim, S.S., Lee, J., \& Prideaux, B. (2014). Effect of celebrity endorsement on tourists' perception of corporate image, corporate credibility and corporate loyalty. International Journal of Hospitality Management, 37, 131-145.

33. Lee, P.K.C., To, W.M., \& Yu, B.T.W. (2009). The implementation and performance outcomes of ISO 9000 in service organizations: an empirical taxonomy. International Journal of Quality and Reliability Management, 26, 646-662.

34. Martínez-Martínez, A., Cegarra-Navarro, J.G., \& García-Pérez, A. (2018). Improving environmental management systems by ISO 9001 in the Spanish hospitality sector. In A. LealMillan et al. (eds), Sustainability in innovation and entrepreneurship, innovation, technology, and knowledge management, Springer International Publishing, 87-101.

35. Molina, J.F., Tarí, J.J., Claver, E., \& López, M.D. (2009). Quality management, environmental management and firm performance: a review of empirical studies and issues of integration. International Journal of Management Reviews, 11, 197-222.

36. Nair, A., \& Prajogo, D. (2009). Internalisation of ISO 9000 standards: the antecedent role of functionalist and institutionalist drivers and performance implications. International Journal of Production Research, 47, 4545-4568.

37. Naveh, E., \& Marcus, A. (2005). Achieving competitive advantage through implementing a replicable management standard: installing and using ISO 9000. Journal of Operations Management, 24, 1-26.

38. OECD (2018). OECD Tourism trends and policies 2018. Retrieved 12 March 2019, from source https://read.oecd-ilibrary.org/urban-rural-and-regional-development/oecd-tourism-trends-andpolicies-2018_tour-2018-en\#page1.

39. Pereira-Moliner, J., Claver-Cortés, E., Molina-Azorín, J.F., \& Tarí, J.J. (2012). Quality management, environmental management and firm performance: direct and mediating effects in the hotel industry. Journal of Cleaner Production, 37, 82-92.

40. Posinska, B., Dahlgaard, J.J., \& Antoni, M. (2002). The state of ISO 9000 certification: a study of Swedish organizations. The TQM Magazine, 14, 297-306.

41. Prajogo, D.I. (2011). The roles of firms' motives in affecting the outcomes of ISO 9000 adoption. International Journal of Operations \& Production Management, 31, 78-100.

42. Psomas, E.L., Kafetzopoulos, D.P., \& Fotopoulos, D.V. (2013). Developing and validating a measurement instrument of ISO 9001 effectiveness in food manufacturing SMEs. Journal of Manufacturing Technology Management, 24, 52-77.

43. Psomas, E.L., Pantouvakis, A., \& Kafetzopoulos, D.P. (2013). The impact of ISO 9001 effectiveness on the performance of service companies. Managing Service Quality, 23, 149-164.

44. Samson, D., \& Terziovski, M. (1999). Relationship between total quality management practices and operational performance. Journal of Operations Management, 17, 393-409.

45. Sánchez-Ollero, J.L., García-Pozo, A., \& Marchante-Mera, A. (2014). Análisis de la incidencia de las certificaciones de calidad sobre la productividad de los hoteles de Andalucía. Universia Business Review, 44, 88-103.

46. Sharma, D.S. (2005). The association between ISO 9000 certification and financial performance. The International Journal of Accounting, 40, 151-172.

47. Sila, I., \& Walczak, S. (2017). Universal versus contextual effects on TQM: a triangulation study using neural networks. Production Planning \& Control, 28, 367-386.

48. Singh, P.J. (2008). Empirical assessment of ISO 9000 related management practices and performance relationships. International Journal of Production Economics, 113, 40-59. 


\section{JOURNAL OF TOURISM AND SERVICES}

Issue 21, volume 11, ISSN 1804-5650 (Online)

www.jots.cz

49. Tarí, J.J., Molina, J.F., \& Castejón, J.L. (2007). The relationship between quality management practices and their effects on quality outcomes. European Journal of Operational Research, 183, 483501.

50. Tarí, J.J., Molina-Azorín, J.F., Pereira-Moliner, J., \& López-Gamero, M.D. (2020). Internalization of Quality Management Standards: A Literature Review. Engineering Management Journal, 32, 46-60.

51. UNWTO (2018). UNWTO Tourism Highlights 2018 Edition. Madrid: World Tourism Organization. Retrieved 12 March 2019, from source https://www.eunwto.org/doi/pdf/10.18111/9789284419876.

52. Wagner, M. (2009). Innovation and competitive advantages from the integration of strategic aspects with social and environmental management in European firms. Business Strategy and the Environment, 18, 291-306.

53. Withanachchi, N., Handa, Y., Karandagoda, K.K.W., Pathirage, P.P., Tennakoon, N.C.K., \& Pullaperuma, D.S.P. (2007). TQM emphasizing 5-S principles. A breakthrough for chronic managerial constraints at public hospitals in developing countries. International Journal of Public Sector Management, 20, 168-177.

54. Yeh, C.M. (2013). Tourism involvement, work engagement and job satisfaction among frontline hotel employees. Annals of Tourism Research, 42, 214-239.

55. Yeung, A.C.L., Chan, L.Y., \& Lee, T.S. (2003). An empirical taxonomy for quality management systems: a study of the Hong Kong electronics industry. Journal of Operations Management, 21, 4562.

\section{Brief description of Authors:}

Dr Juan José Tarí (jj.tari@ua.es), Full Professor in Business Management at the University of Alicante, Spain. His Ph. D. dissertation was an analysis of quality management. His current research includes Total Quality Management and its relationship with social responsibility, environmental management, organization design, innovation and higher education.

Dr Jorge Pereira-Moliner (jorge.pereira@ua.es), Associate Professor in Business Management at the University of Alicante, Spain. His Ph. D. dissertation was an analysis of strategic groups in the hotel industry. His current research includes strategic management and strategic groups of the hotel industry, and quality and environmental management.

Dr Jose F. Molina-Azorín (jf.molina@ua.es), Associate Professor in Business Management at the University of Alicante, Spain. His research focuses on strategic management and environmental management, specifically the determinants of firm performance, the competitive effects of environmental management and the relationship between competitive strategy and organizational design. His current research interests are also focused on mixed methods research.

Dr María D. López-Gamero (md.lopez@ua.es), Associate Professor in Business Management at the University of Alicante, Spain. Her Ph. D. dissertation was an analysis of the relationship between environmental management and firm performance. Her current research includes sustainable tourism, environmental management and its relationship with quality management and organizational design. 